\title{
INSTRUMENTOS ALTERNATIVOS DE FINANCIACIÓN PARA LAS COOPERATIVAS ESPAÑOLAS
}

\author{
POR \\ Luis Ángel SÁNCHEZ PACHÓN ${ }^{1}$
}

\section{RESUMEN}

La búsqueda de financiación constituye un quehacer permanente de la empresa, que se agudiza, particularmente, en los momentos de crisis económica y afecta, también, a las cooperativas. La legislación cooperativa pone a disposición de estas entidades diversos instrumentos de financiación externa a través de la emisión de valores (obligaciones; títulos participativos; participaciones especiales), a ellos se añaden las cuentas en participación, aunque sin mucho detalle en los textos legales. En el trabajo indagamos sus posibilidades, fijándonos, especialmente, en esas últimas; buscamos clarificar su régimen jurídico y contrastar sus potencialidades como un instrumento técnico, alternativo, para la financiación en el ámbito de las sociedades cooperativas. En fin, vemos también la incidencia de la reciente Ley 5/2015, de fomento de la financiación empresarial, en el sector del cooperativo y terminamos proponiendo algunas adaptaciones normativas.

Palabras clave: Legislación cooperativa, cuentas en participación, contrato de participación; fomento de la financiación.

Claves ECONLIT: P13; K12; G19.

\section{ALTERNATIVE FINANCING INSTRUMENTS FOR SPANISH COOPERATIVE}

\section{ABSTRACT}

The search for funding is an ongoing task of the company, which is exacerbated, particularly in times of economic crisis, affecting also to the cooperatives. Cooperative legislation available to these entities various instruments of external financing through the

1 Departamento de Derecho Mercantil. Universidad de Valladolid. Dirección de correo electrónico: pachon@eco.uva.es.

REVESCO No 122 - Tercer Cuatrimestre 2016 - ISSN: 1885-8031 - www.ucm.es/info/revesco

http://dx.doi.org/10.5209/rev_REVE.2016.v122.52023

Fecha de recepción: 29/10/2015

Fecha de aceptación: 01/03/2016 
issuance of securities (bonds, equity securities, special shares), to them accounts are added in participation, but without much detail in the legal texts. At work we investigate their potential, by looking, especially in those last; We seek to clarify their legal status and contrast their potential as a technical instrument, alternative for funding in the area of cooperative societies. Finally, we also see the impact of the recent Law 5/2015, of promoting business financing in the cooperative sector and ended up proposing some policy adjustments.

Keywords: Cooperative legislation, participation accounts, participation contract; promoting funding.

\section{INTRODUCCIÓN}

La crisis económica que hemos venido padeciendo ha puesto de manifiesto, entre otras cosas, la excesiva dependencia del sector bancario al que se ven sometidas las empresas, particularmente pequeñas y medianas, cuando precisan de financiación. La búsqueda de financiación constituye un quehacer permanente de la empresa que se ve dificultada en los momentos de crisis económica y que, evidentemente, se agudiza cuando los protagonistas de la crisis vienen siendo los principales valedores de la financiación que se necesita.

Las cooperativas no son ajenas a esta problemática. La legislación cooperativa pone a disposición de esas entidades diversos instrumentos de financiación externa a través de la emisión de valores (obligaciones; títulos participativos; participaciones especiales) a los que se suele añadir, aunque sin mucho detalle en los textos legislativos, las cuentas en participación.

Con este trabajo buscamos conocer mejor los instrumentos normativos de financiación disponibles por las entidades cooperativas; contrastar sus posibilidades y, a la vez, indagar nuevas técnicas y fórmulas jurídicas que puedan actuar, de algún modo, como alternativa o complemento a los instrumentos tradicionales de financiación, y proponer, también, las adaptaciones normativas convenientes. Todo ello sin perder de vista la nueva regulación que se ofrece en la Ley 5/2015, de 27 de abril (BOE del 28), de fomento de la financiación empresarial, donde se contemplan, por primera vez, las Plataformas de Financiación Participativa (PFP), cuyo papel e incidencia en el sector cooperativo parece escaso, pero que, de cualquier modo, pretendemos también clarificar. 
Para ello, habiendo constatado que la búsqueda de financiación de las empresas viene a ser un problema recurrente y que, en nuestro País, la financiación proveniente de las entidades bancarias del sector privado, ha sido y sigue siendo la preponderante; constatada, también, la escasa atención a la emisión de valores, que se presta en la legislación cooperativa como medio de financiación externa, analizamos los instrumentos de financiación existentes en la legislación cooperativa española, reseñamos las modificaciones operadas por la Ley 5/2015, de 27 de abril y, particularmente, nos centramos en las posibilidades de las cuentas en participación como instrumento de financiación, en cierta medida alternativa, para las sociedades cooperativas.

\section{LA BUSQUEDA DE FINANCIACIÓN COMO PROBLEMA PERMANENTE: LA EXCESIVA DEPENDENCIA EN ESPAÑA DE LA FINANCIACIÓN BANCARIA}

Hace unos años el profesor Rocafort Nocolau apuntaba que la necesidad de financiación de nuestras empresas es una cuestión recurrente que se ha visto agravada por razón de la crisis económica, y que a esta consideración general no se escapaban las sociedades cooperativas, como lo corroborará la reducción del número de las entidades y el incremento del número de las situaciones concursales. (Rocafort, 2010: 143). Tampoco en los momentos actuales se escapan a esta necesidad los agentes que hoy las legislaciones acostumbran a tratar como protagonistas del emprendimiento o de las iniciativas emprendedoras y que, en el fondo, buscan iniciar o promover actividades empresariales.

En efecto, el principal problema que tiene la iniciativa emprendedora, en la actualidad y en sus distintas formas, es el de la financiación (Alemany, Álvarez, Planellas, Urbano, 2011: 16 y ss.), por encima del factor cultural, educativo y administrativo ${ }^{2}$.

Por otra parte, como antes apuntábamos, la excesiva dependencia de la financiación bancaria que experimentan, particularmente, la pequeña y mediana empresa en nuestro país, ha dificultado y dificulta sobremanera las posibilidades de acceder a una financiación necesaria, toda vez que el sector bancario ha estado en los orígenes y ha sido uno de los

\footnotetext{
${ }^{2}$ En el informe de Agencia Estatal de Evaluación de las políticas públicas y la calidad de los servicios (AEVAL) sobre Trámites Administrativos para la creación de empresas en España, edición de 2008, se venía a concluir que para el $49 \%$ de los emprendedores los problemas financieros son más importantes que las trabas administrativas (40\%), como elementos disuasorios a la hora de constituir una empresa. Resulta también muy esclarecedora la Tabla que en el informe de AEVAL de 2012 recoge la clasificación de las fuentes citadas por los expertos como generadoras de obstáculos a la actividad emprendedora en España en 2011 donde el apoyo financiero, las políticas gubernamentales, las normas sociales y culturales, el clima económico figuran como los primeros obstáculos para la actividad emprendedora; y se constata cómo la financiación aparece como el problema fundamental a la hora de poner en marcha una iniciativa emprendedora.
} 
principales protagonista de la profunda crisis económica que hemos sufrido; lo que no puede dejar de repercutir en el presente y futuro más inmediato.

El mismo Preámbulo de la Ley 5/2015, de 27 de abril, de fomento de la financiación empresarial (BOE del 28), comienza afirmando que las empresas españolas han sido tradicionalmente muy dependientes de la financiación bancaria, tanto para sus necesidades de inversión como para su operativa corriente, y que esta dependencia es todavía más acusada en el caso de las empresas de menor dimensión. Los efectos de esta fuerte bancarización -se reconoce- se ha dejado notar en la economía española en los últimos años. Si durante la etapa de expansión económica el crédito a las empresas no financieras y a los hogares creció a tasa que triplicaban el crecimiento económico, desde el año 2009 se ha producido una acusada reducción del crédito, que se ha intensificado en los años 2012 y 2013, acompañada, además, con un paralelo incremento de su coste.

Nuestra prensa económica se ha hecho eco de esta problemática y ha recogido alguna opinión de los expertos del mundo financiero: “en España tiene que haber un proceso de desintermediación bancaria, es la única forma de que cuando la economía vuelva a crecer, lo haga de forma sana. Hay muchas limitaciones desde Bruselas y la banca no va poder financiar como antes" 3 .

Es cierto que en todos los países europeos la financiación bancaria ocupa un lugar destacado en las fuentes de financiación, particularmente, de las pequeñas y medianas empresas, pero también lo es que en España la financiación bancaria ha venido ocupando unos porcentajes probablemente excesivos si los comparamos con los países de nuestro entorno. En este sentido, es ilustrativo el estudio que hace la profesora Torre Olmo, donde se refleja que el crédito bancario en España ronda el 70\% (Torre, 2013). Situación que, como recogía también A. Hernández en el diario El Mundo, difiere de la de los países de la Eurozona 4 .

Se hace necesario, pues, buscar y ensayar fórmulas o soluciones alternativas a un tipo de financiación excesivamente bancarizada. En esas fórmulas alternativas, quizá, las cuentas en participación, de las que aquí nos ocuparemos particularmente, puedan ofrecer una instrumentalización adecuada para una financiación privada y no bancaria.

\footnotetext{
${ }^{3}$ Vid. Cinco Días 02/10/2014 http://cincodias.com/cincodias/2014/10/02/mercados/1412273056 056147.html

${ }^{4}$ Vid. https://www.ucm.es/data/cont/media/www/pag-53122/agonia\%20obra\%20social.pdf
} 
Además de las fuente de financiación comunes en el ámbito empresarial, se suelen señalar, particularmente en el ámbito de la actual iniciativa emprendedora, las siguientes fuentes de financiación: préstamos bancarios, capital riesgo (venture capital), ángeles inversores (business angels) y otras fuentes, en cierto sentido alternativas, como pueden ser los distintos métodos que reducen los requerimientos de capital, mejorando el flujo de caja y aprovechando las fuentes personales de financiación (por ejemplo, a través del uso de tarjetas de crédito; retrasando el pago a los proveedores; retrasando el pago de impuestos, compartiendo el equipo o los empleados con otras empresas, utilizando distintos sistemas de arrendamiento financiero, etc.).

Entre todas esas fuentes de financiación que se exploran en la actualidad, destacamos la de los “ángeles inversores”, porque, quizá, sea la fórmula que más proyección pueda ofrecer. Esos ángeles inversores son personas que invierten su propio dinero o sus conocimientos en proyectos con alto potencial de crecimiento, generalmente en fases muy tempranas de su desarrollo, a cambio de una participación en la empresa. También contribuyen con su experiencia y su red personal de contactos en la gestión empresarial. En algunos casos los business angels se asocian en clubs de inversión, a veces denominadas redes de business angels. La presencia de estas redes les facilita la actividad inversora a través de foros de inversión, en los que los empresarios o emprendedores, que se encuentran buscando capital, presentan sus proyectos a la red. Las posibilidades de estas redes son evidentes y, en nuestro ordenamiento jurídico, un instrumento jurídico que -pensamos nosotros- puede facilitar la participación de los inversores en los proyectos empresariales son las cuentas en participación; a veces conocidas en el ámbito mercantil también como contratos de participación.

Conviene, pues, clarificar el régimen jurídico de las distintas figuras previstas en la legislación cooperativa, para contrastar todas sus posibilidades y, sobre todo, para exponer la virtualidad funcional que presentan las cuentas en participación y las oportunidades que ofrecen como técnica de financiación en el ámbito de las sociedades cooperativas. Todo ello porque, como se ha venido a decir, una de las razones del éxito o del fracaso de los instrumentos o técnicas de financiación, en cualquier ámbito y también en el de las sociedades cooperativas, lo está en el ofrecimiento de unos perfiles claros y fácilmente identificables por los inversores (Gadea; Sacristán; Vargas, 2009: 415). 


\section{INSTRUMENTOS JURÍDICOS PARA LA FINANCIACIÓN EN LA} LEGISLACIÓN COOPERATIVA ESPAÑOLA: LA EMISIÓN VALORES (OBLIGACIONES; TÍTULOS PARTICIPATIVOS; PARTICIPACIONES ESPECIALES)

La legislación cooperativa pone a disposición de estas entidades diversos instrumentos de financiación o de captación de recursos. Algunos de esos instrumentos o técnicas de financiación son de incorporación relativamente reciente en el ámbito de las entidades cooperativas, como ocurre con los títulos participativos o las participaciones especiales. Otras veces se nos han presentado como novedades lo que no son más que variaciones de instrumentos existentes; quizá en la creencia de que la creación de una nueva figura incrementa su tractivo y su utilización (Rocafort, 2010: 151; Celaya, 1995: 144).

Como se ha puesto en evidencia por la doctrina científica, muchas figuras jurídicas confluyen entre sí: participaciones especiales, títulos participativos, obligaciones, financiación voluntaria a través de emisiones en serie; pudiendo encajar, de una u otra forma y aun con las diferencias que en seguida constataremos, en el marco de los préstamos subordinados. Esta confluencia lleva a cuestionar a algunos autores la conveniencia de crear tantas figuras, con perfiles frecuentemente difusos, y desconocidas por el público inversor; lo que hace, incluso, reconsiderar el uso de instrumentos más conocidos en el mercado y susceptibles de mayor credibilidad social (Gadea et al., 2009: 414) .

A la hora de clasificar las distintas vías o instrumentos que la legislación cooperativa española pone al servicio de las cooperativas para la captación de recursos financieros, al margen del capital, los autores, a veces, diferencian entre formas de financiación tradicionales (cuotas de ingreso; cuotas periódicas; préstamos en general; obligaciones y otras emisiones en serie; cuentas en participación) y formas de financiación modernas (participaciones especiales; títulos participativos) (Gadea et al., 2009: 406). Algunos autores, no obstante; tras aprobarse la Ley 27/1999, de Cooperativas, distinguía entre fórmulas clásicas de financiación y nuevas fórmulas de financiación, conforme a la ley 27/1999, incluyendo en este segundo grupo las cuentas en participación Fernández, 2002: 8). Otros autores, dentro de las

\footnotetext{
${ }^{5}$ En esa misma línea, esos autores se atreven a proponer la autorización de emisiones de capital comanditario. La figura desempeñaría un papel similar al de las acciones sin voto en la sociedad anónima. Quizá sea oportuno recordar aquí cómo las cuentas en participación se han visto también como una alternativa para la financiación de las sociedades de responsabilidad limitada. supliendo algunas funciones, que en el ámbito de las sociedades anónimas, desempeñan las acciones sin voto (Rodríguez, 1999: 489 y ss.).
} 
prestaciones que no integran el capital, distinguen las cuotas de ingreso y las cuotas periódicas; las participaciones especiales; y otros mecanismos de financiación voluntaria de socios y terceros, donde se incluyen la emisión de obligaciones u otros valores, además de los préstamos y de los contratos de cuentas en participación (Paniagua, 2005: 266 y ss.). Y hay quienes agrupan los instrumentos de financiación en dos grandes bloques: financiación mediante emisión de valores (obligaciones y otros valores específicos de las cooperativas) y financiación mediante mecanismos alternativos (incluyendo aquí las cuentas en participación y las subvenciones) (López, 2013: 225).

Respecto a la financiación mediante la emisión de valores, conviene ahora advertir que todo el régimen de la emisión de obligaciones ha sido reformado por la Ley 5/2015, de 27 de abril, de fomento de la financiación empresarial, que, además y como veremos después, ha incorporado ciertas novedades en la emisión de obligaciones por las sociedades cooperativas. La reforma permite así actualizar una regulación anticuada e insuficiente, como la de la Ley 211/ 1964, de 24 de diciembre, a la que se sometían las sociedades que no hubieran adoptado la forma de sociedades anónimas, las asociaciones u otras personas jurídicas, y que no resolvía adecuadamente todos los problemas que se pueden presentar en la emisión de obligaciones por la sociedad cooperativa (Gadea, et al., 2009: 408).

Los títulos participativos se contemplan en todas las leyes, si bien, la doctrina suele concluir que la distinción entre la posibilidad de emitir obligaciones y títulos participativos es más bien pedagógica o de imagen, y que el título participativo no deja de ser una obligación con un sistema de remuneración distinto al usual, además del reconocimiento de un posible derecho de asistencia a la Asamblea General y, en algún caso, al Consejo Rector (Gadea et al., 2009: 413).

Con todo, conviene resaltar que lo característico de los títulos participativos es la remuneración mixta a la que tienen derecho sus titulares. Una remuneración mixta que la suele formar un interés fijo más la parte variable que se establezca en el momento de la emisión, en función de los resultados de la cooperativa.

Otra diferencia con la emisión de obligaciones es que la de títulos participativos, generalmente, se atribuye a la Asamblea General. Así se ha visto confirmado en la Ley de Cooperativas tras la reforma de sus artículos 21.2 letra e) y 32.1, producida por la Ley 5/2015, de 27 de abril, de fomento de la financiación empresarial. 
En efecto, ese artículo 21.2, que se ocupa de recoger las competencias exclusivas de deliberación y toma de acuerdos de la Asamblea General, en su letra e) dispone literalmente: “e) Emisión de títulos participativos y participaciones especiales”. Con anterioridad a esta reforma se recogían en esa misma letra, también, la emisión de obligaciones y otras formas de financiación mediante emisión de valores negociables.

Por su parte, al referido artículo 32.1, que recoge las competencias del Consejo Rector, se le añade ahora un párrafo final en el que literalmente se dispone:

“Asimismo, le corresponde acordar, salvo disposición contraria en los Estatutos sociales, la emisión de obligaciones y otras formas de financiación mediante emisión de valores negociables, siempre y cuando no se trate de títulos participativos o participaciones especiales, cuya competencia está atribuida a la Asamblea General.”

Más complejidad aparece en las llamadas participaciones especiales, que, además, no presentan idéntico tratamiento en la legislación autonómica (López, 2013: 634 y ss.). En términos generales son aportaciones patrimoniales realizadas por socios o terceros que, normalmente, se consideran deuda subordinada y, por asimilación, pueden tener el tratamiento de los fondos propios. La peculiaridad más significativa es que su reembolso no puede tener lugar hasta que transcurran, al menos, 5 años, aunque algunas leyes lo fijan en 10 y otras, incluso, como hace el artículo 53.1 de la Ley 27/1999, de Cooperativas, recogen la posibilidad de que su vencimiento no tenga lugar hasta la aprobación de la liquidación de la sociedad emisora, teniendo la consideración, en estos casos, de capital social (Gadea et al., 2009: 411; Martínez, 2014: 298-299).

No cabe duda que la configuración de las participaciones especiales, permitiendo la captación de recurso externos reembolsables a largo plazo, tiene la ventaja de ofrecer una financiación estable, que, incluso, si su vencimiento no tiene lugar hasta la aprobación de la liquidación de la entidad emisora, conformará un fondo estable de capital propio. Lo que, a priori, hace que no presenten mucho atractivo para los inversores, sobre todo si el vencimiento de las participaciones se hace coincidir con el de la aprobación de la liquidación de la sociedad emisora, que, lógicamente suele ser una aspiración habitual de la entidad (López, 2013: 636-337) ${ }^{6}$, en cuyo caso, además, el reembolso a los partícipes se habrá de

\footnotetext{
${ }^{6}$ Como viene a añadir esta autora, para hacer atractivas esas participaciones a los inversores, algunas normas prevén la posibilidad de que sean reembolsadas antes de su vencimiento, constituyendo una reserva por el importe de los fondos reembolsados, o el reconocimiento en favor de sus titulares, y en concepto de
} 
realizar después del pago de los otros créditos. Lo mismo que ocurrirá, como deuda subordinada que es, en el caso de concurso de acreedores de la cooperativa, lo que dificulta de manera notable la recuperación de la inversión realizada por los inversores -el caso de las aportaciones financieras subordinadas de Fagor Electrodomésticos S.Coop., tras la declaración de su concurso, constituye un doloroso ejemplo- toda vez que esos inversores se situarán detrás de todos los acreedores y solo por delante de los socios (Martínez, 2014: 299).

Por lo demás, la emisión de las participaciones especiales requiere del acuerdo de la Asamblea General, en el que se fijará el régimen concreto de las participaciones (plazo de reembolso, remuneración etc.) y, en su caso -y como confirma el art. 53.2 de la Ley 27/1999, de Cooperativas- el cumplimiento de los requisitos establecidos en la normativa reguladora del mercado de valores. Esta competencia atribuida a la Asamblea General, al igual que ocurre con la emisión de títulos participativos, se ha visto confirmada en la Ley de Cooperativas, tras la reforma de sus artículos 21.2 letra e) y 32.1, producida por la Ley 5/2015, de 27 de abril, de fomento de la financiación empresarial, como antes apuntamos.

Al lado de estos métodos de financiación, las legislaciones cooperativas suelen aludir a las cuentas en participación. La doctrina, frecuentemente, ha considerado las cuentas en participación como un método de financiación tradicional; a veces, incluso, se ha dicho que es propio de épocas anteriores o primitivas (Gadea et al. 2009: 408; Bel y Fernández, 2002: 124; Fernández, 2002: 23; Marín, 1999: 49). Ciertamente, como nos recuerda Martínez Balmaseda, teniendo un origen en la Edad Media, las cuentas en participación constituyen una institución tradicional en el ámbito del Derecho Mercantil y se presentan como una figura evolucionada de la commenda medieval, que constituye la forma más antigua de cooperación y origen histórico de numerosas instituciones mercantiles. Con todo, como constata esta autora, más allá de la función tradicional, hoy día las cuentas en participación siguen estando presentes en nuestra práctica jurídica y, además, tienen una presencia más destacada de lo que a primera vista pueda parecer (Martínez, 2011: 95-96).

Sea como fuere, al margen de la alusión, poco más hacen las leyes de cooperativas, limitándose a remitir su régimen a lo que se prevé en el Código de comercio; lo que no deja

remuneración, del derecho a un dividendo concreto sobre los excedentes obtenidos en cada ejercicio. Con todo, como bien apunta la autora, lo más importante, como ocurre con la generalidad de los instrumentos de inversión, es el grado de su liquidez, por lo que resultará conveniente que no se establezcan importantes limitaciones a su transmisibilidad y que se emitan, cuanto menos, agrupadas en emisiones, y no de forma aislada, participando así de la naturaleza de los valores negociables. 
de generar incertidumbres, porque, hoy por hoy, la regulación que contienen los artículos 239 a 243 de ese Código, no termina de dar respuesta a los conflictos que pueden surgir de la relación de participación que la figura contempla.

El profesor Fernández de la Gándara resaltaba el clima de permanente indefinición y debate en el que, desde sus orígenes, ha vivido el desarrollo y estatuto legal de las cuentas en participación (Fernández, 1998: 259 y ss.). Las deficiencias de la escasa disciplina legal, que nos presenta en el Código de comercio, no pueden dar respuesta satisfactoria a las muchas y complejas cuestiones que la figura plantea en el tráfico mercantil. La regulación aparece contaminada de elementos normativos y consideraciones exegéticas que tampoco en la literatura mercantil han estado libres de crítica (Sánchez, 2009: 549 y ss.).

Lo que todavía hoy es Anteproyecto de Ley del Código mercantil, que fue presentado por los Ministerios de Justicia y de Economía y Competitividad el 30 de mayo de 2014, y que estaría llamado a sustituir, además del viejo Código de comercio de 1885, a buena parte de la normativa mercantil, recoge, dentro del Libro Quinto de los Contratos Mercantiles en particular, Título I, De los contratos de colaboración, en el Capítulo V, el contrato de participación (artículos 545.1 a 545.5); figura que en lo esencial -como reconoce también la exposición de motivos del texto- coincide con la figura de las cuentas en participación que contempla el vigente Código de comercio.

Todos estos datos, entendemos, justifican retomar el estudio y otear en las posibilidades que ofrecen las cuentas en participación, o contrato de participación, como prefiere llamarlo lo que tendría que de ser nuevo Código mercantil, si bien, a día de hoy, disu4eltas las Cámaras, habrá de esperarse a la nueva legislatura.

\section{LAS CUENTAS EN PARTICIPACIÓN COMO INSTRUMENTO DE FINANCIACIÓN EN LAS COOPERATIVAS ESPAÑOLAS}

\subsection{Regulación nacional y autonómica}

El artículo 54 de la Ley 27/1999, de 16 de julio, de Cooperativas, en su nueva redacción, bajo el rótulo de otras financiaciones y después de prever la posibilidad -salvo que los Estatutos sociales dispongan otra cosa- de que el Consejo Rector ${ }^{7}$ pueda acordar la

\footnotetext{
${ }^{7}$ En la nueva redacción dada al artículo 54.1 por la Ley 5/2015, de 27 de abril, de fomento de la financiación empresarial (BOE del 28), es al Consejo Rector al que se atribuye la competencia, salvo que los Estatutos
}

REVESCO No 122 - Tercer Cuatrimestre 2016 - ISSN: 1885-8031 - www.ucm.es/info/revesco 
emisión de obligaciones (art. 54.1) y de que la Asamblea General pueda acordar la emisión de títulos participativos (art. 54.2), en su número 3, recoge también la posibilidad de concordar cuentas en participación; aunque se limita a decir que También podrán contratarse cuentas en participación cuyo régimen se ajustará a lo establecido por el Código de Comercio.

El vigente Código de Comercio contempla la figura de la cuentas en participación en los artículo 239 a 243.

De todo ello un sector doctrinal deduce que "no hay obstáculo para que la cooperativa pueda contratar cuentas en participación como aportante, por lo que podría asumir en los diversos contratos que concierte, bien la posición de gestora, bien la de cuenta partícipe" (Morillas J y Feliú, 2002: 415; López, 2013: 640-641; Paniagua, 2005: 271). En nuestra opinión, sin embargo, el hecho de que las cuentas en participación se recojan dentro de las formas de financiación (como otras financiaciones) de la cooperativa -lo que generalmente se hará también en la legislación autonómica- lleva a concluir que, en la relación jurídica de las cuentas en participación que está contemplando el legislador, la cooperativa únicamente pueda asumir la figura de gestor y no la de cuentapartícipe. Lo da a entender así, también Gadea Soler (Gadea, 2003: 52). La posibilidad de que una cooperativa concierte unas cuentas en participación como cuentapartícipe, entendemos nosotros, cae fuera de la previsión de aquel artículo 54 y solo sería posible en la medida que lo permitiera su objeto social o en la medida en que pudiera constituir una forma de colaboración económica al amparo de lo dispuesto en el artículo 79 de la LC.

En la legislación autonómica de cooperativas nueve leyes prevén expresamente la posibilidad de celebrar contratos de cuentas en participación, generalmente también contemplados como medios alternativos o complementarios de financiación de la entidad. Sin embargo, fuera de una remisión genérica a la regulación específica que establece el Código de comercio (artículos 239 a 243), poco más suele añadirse. Esas nueve leyes autonómicas son las que a continuación se indican:

Ley 11/2010, de 4 de noviembre, de Cooperativas de Castilla-La Mancha. Artículo $83.6^{8}$

dispongan otra cosa. En la redacción anterior era la Asamblea General la que podía acordar la emisión de obligaciones.

${ }^{8}$ Artículo 83. Modalidades de financiación no integrantes del capital social... 
La Ley 12/2015, de 9 de julio, de cooperativas de Cataluña, que deroga la anterior la Ley 18/2002, de 5 de julio, de Cooperativas de Cataluña, en su artículo 76.4, con idéntica redacción al artículo 61.4 de la derogada Ley 18/2002 ${ }^{9}$.

Ley 2/1998, de 26 de marzo, de Sociedades Cooperativas de Extremadura. Artículo 59.2 $2^{10}$.

Ley 5/1998, de 18 de diciembre, de Cooperativas de Galicia. Artículo $65.6^{11}$.

Ley 1/2003 de 20 de marzo de Cooperativas de las Illes Balears. Artículo $78.3^{12}$

Ley 4/2001, de 19 de julio, de Cooperativas de La Rioja. Artículo 69 redactado por el apartado noveno del artículo 37 de la Ley 13/2013, 23 diciembre, de Medidas Fiscales y Administrativas para el año $2014^{13}$.

Ley Foral 14/2006, de 11 de diciembre, de Cooperativas de Navarra. Artículo $45.11^{14}$.

6.- También podrán contratarse cuentas en participación, ajustándose su régimen a lo establecido por el Código de Comercio.

${ }^{9}$ Artículo 76. Prestaciones y financiación que no integran el capital social...

4. La asamblea general puede acordar la admisión de financiación voluntaria de los socios o de terceras personas, bajo cualquier modalidad jurídica y en el plazo y con las condiciones que se establezcan en el propio acuerdo. Dicha financiación en ningún caso ha de integrar el capital social. También pueden contratarse cuentas en participación cuyo régimen tiene que ajustarse a la legislación vigente.

${ }^{10}$ Artículo 59. Otras formas de financiación...

2. Asimismo, la Asamblea General podrá acordar la contratación de cuentas de participación cuyo régimen se ajustará a lo establecido en el Código de Comercio.

${ }^{11}$ Artículo 65 Financiaciones que no integran capital social...

6.- También podrán contratarse cuentas en participación, ajustándose su régimen a lo establecido por el Código de comercio.

${ }^{12}$ Artículo 78 Otras financiaciones

3. También puede contratarse cuenta en participación, ajustándose su régimen al previsto en el Código de Comercio.

${ }^{13}$ Artículo 69 Aportaciones que no forman parte del capital social

6. También podrán contratarse cuentas en participación, ajustándose su régimen a lo establecido en el Código de Comercio.

${ }^{14}$ Artículo 45 Capital social...

11. Igualmente podrá acordar la Asamblea General la emisión de títulos participativos que no integren el capital social, los cuales darán derecho a la correspondiente remuneración mixta en forma de interés fijo más una parte variable en la proporción que, en función de los resultados de la cooperativa, aquella establezca en el momento de la emisión.

El acuerdo de la Asamblea General al respecto concretará el plazo de amortización y las demás normas de aplicación, así como el derecho de asistencia de los titulares de las participaciones a las sesiones de la Asamblea General con voz y sin voto.

También podrá acordarse por la Asamblea General la contratación de cuentas en participación cuyo régimen se ajustará a lo establecido por el Código de Comercio. 
Ley del Principado de Asturias 4/2010, de 29 de junio, de Cooperativas. Artículo 95.1 y $5^{15}$.

Ley 4/1993, de 24 de junio, de Cooperativas de Euskadi. Artículo $65.6^{16}$.

De la legislación de cinco Comunidades Autónomas podríamos deducir que, de una manera u otra, aunque sin mencionarlo expresamente, terminan posibilitando también la concertación de cuentas en participación como medio de financiación de la entidad cooperativa. Las leyes de esas cinco Comunidades son las siguientes:

Ley 14/2011, de 23 de diciembre, de Sociedades Cooperativas Andaluzas. Artículo $62.3^{17}$.

El Decreto Legislativo 2/2014, de 29 de agosto, del Gobierno de Aragón, por el que se aprueba el texto refundido de la Ley de Cooperativas de Aragón. Artículo $55.3^{18}$.

Ley 4/2002, de 11 de abril, de Cooperativas de la Comunidad de Castilla y León. Artículo $70.2^{19}$.

Ley 8/2003, de 24 de marzo, de Cooperativas de la Comunidad Valenciana. Artículo $62.3^{20}$.

\footnotetext{
${ }^{15}$ Artículo 95 Otras financiaciones

1. La asamblea general podrá acordar la financiación voluntaria de la cooperativa procedente de los socios y de terceros, bajo cualquier modalidad jurídica y en el plazo y condiciones que se establezcan en el acuerdo.

5. También podrán contratarse cuentas en participación cuyo régimen se ajustará a lo establecido por el Código de Comercio.

${ }^{16}$ Artículo 65 Otras financiaciones...

6. También podrán contratarse cuentas en participación cuyo régimen se ajustará a lo establecido por el Código de Comercio.

${ }^{17}$ Artículo 62. Aportaciones no integradas en el capital social y otras formas de financiación...

3. La Asamblea General podrá acordar la financiación voluntaria por parte de las personas socias, o no socias, bajo cualquier modalidad jurídica y en el plazo y condiciones que se establezcan en el correspondiente acuerdo, sin que la misma integre el capital social.

${ }^{18}$ Artículo 55 Formas de financiación no integradas en el capital social...

3. La Asamblea general podrá acordar la admisión de financiación voluntaria procedente de los socios y terceros, bajo cualquier modalidad y en el plazo y condiciones que se establezcan en el acuerdo.

${ }^{19}$ Artículo 70. Otras formas de financiación...

2. La Asamblea General puede acordar la admisión de financiación voluntaria de los socios, bajo cualquier modalidad jurídica y en el plazo y condiciones que se establezcan en el propio acuerdo. En ningún caso integrarán el capital social.

${ }^{20}$ Artículo 62 Otros medios de financiación...

3. La asamblea general puede acordar cualquier modalidad de financiación voluntaria de la cooperativa por sus socios y asociados, que en ningún caso integrará el capital social. Igualmente, podrá emitir obligaciones, subordinadas o no, siempre de carácter no convertible en aportaciones sociales, de acuerdo con la legislación
} 
Ley 4/1999, de 30 de marzo, de Cooperativas de la Comunidad de Madrid. Artículo $57.3^{21}$.

Quizá la excepción la constituyan la Ley de Cantabria 6/2013, de 6 de noviembre, de Cooperativas de Cantabria -recordemos que es la última de las leyes autonómicas aprobada- y la Ley 8/2006, de 16 de noviembre, de Sociedades Cooperativas de la Región de Murcia. La primera en su artículo 69 y la segunda en el 74, prácticamente con idéntica redacción, parecen circunscribir los "otros medios de financiación a "obligaciones", "emisiones en serie" y "títulos participativos",22.

A partir de aquí, con esta regulación, muchas cosas quedan por explicar. No solo su régimen jurídico, pues la remisión genérica al Código de comercio que se hace en la mayoría de los casos, conlleva, irremediablemente y como enseguida veremos, las mismas dudas e inseguridades que, hoy por hoy, presenta esa regulación del Código de comercio. También quedan por explicar cuestiones como la de quién o quiénes puede ser cuentapartícipes: ¿Solo

vigente (redactado por el anexo Diecinueve de la Ley 4/2014, 11 julio, de modificación de la Ley 8/2003, de 24 de marzo, de Cooperativas de la Comunitat Valenciana (DOCV de 17 julio), donde la palabra "aportaciones" ha sustituido a la de "participaciones".

${ }^{21}$ Artículo 57 Otros medios de financiación...

3. La Asamblea General puede acordar cualquier modalidad de financiación voluntaria de la Cooperativa por sus socios o por terceros, que sea conforme con la legislación vigente. Igualmente las Cooperativas podrán emitir obligaciones sin que puedan convertirse en aportaciones sociales al capital, salvo que los obligacionistas fuesen socios.

${ }^{22}$ Ley de Cantabria 6/2013, de 6 de noviembre, de Cooperativas de Cantabria

Artículo 69 Otros medios de financiación

1. Las sociedades cooperativas, por acuerdo de la asamblea general, podrán emitir obligaciones cuyo régimen se ajustará a lo dispuesto en la legislación aplicable. Asimismo, la asamblea general podrá acordar, cuando se trate de emisiones en serie, la admisión de financiación voluntaria de los socios o de terceros no socios bajo cualquier modalidad jurídica y con los plazos y condiciones que se establezcan.

2. La asamblea general podrá acordar la emisión de títulos participativos, que podrán tener la consideración de valores mobiliarios, y darán derecho a la remuneración que se establezca en el momento de la emisión, y que deberá estar en función de la evolución de la actividad de la sociedad cooperativa, pudiendo, además, incorporar un interés fijo.

El acuerdo de emisión, que concretará el plazo de amortización y las demás normas de aplicación, podrá establecer el derecho de asistencia de sus titulares a la asamblea general, con voz y sin voto.

Ley 8/2006, de 16 de noviembre, de Sociedades Cooperativas de la Región de Murcia

Artículo 74 Otros medios de financiación

1. Las sociedades cooperativas, por acuerdo de la Asamblea General, podrán emitir obligaciones cuyo régimen se ajustará a lo dispuesto en la legislación aplicable. Asimismo, la Asamblea General podrá acordar, cuando se trate de emisiones en serie, la admisión de financiación voluntaria de los socios, de los asociados, o de terceros no socios bajo cualquier modalidad jurídica y con los plazos y condiciones que se establezcan.

2. La Asamblea General podrá acordar la emisión de títulos participativos, que podrán tener la consideración de valores mobiliarios, y darán derecho a la remuneración que se establezca en el momento de la emisión, y que deberá estar en función de la evolución de la actividad de la sociedad cooperativa, pudiendo, además, incorporar un interés fijo.

El acuerdo de emisión, que concretará el plazo de amortización y las demás normas de aplicación, podrá establecer el derecho de asistencia de sus titulares a la Asamblea General, con voz y sin voto. 
los socios? ¿Socios y asociados? ¿También los terceros?. Queda por explicar quién o quiénes pueden autorizar las cuentas en participación en la cooperativa y en qué condiciones: ¿La asamblea? ¿El consejo rector? ¿El gerente, si lo tiene? ¿En qué condiciones? ¿Con qué formalidades? ¿En todo tipo de cooperativas? ¿Ha de estar contemplada la posibilidad en los estatutos?... Cuestiones, pues, que quedan abiertas y cuya clarificación habría de contribuir a una mejor y más provechosa utilización de este instituto jurídico como un medio alternativo de financiación de la entidad cooperativa.

\subsection{La genérica remisión a la regulación del código de comercio}

De lo dispuesto en el artículo 239 del vigente Código de comercio, que hemos reproducido más arriba, algunos autores deducen un concepto de cuentas en participación, que suelen configurar como un acuerdo de colaboración en el que una de las partes aporta recursos y la otra gestiona, compartiendo los resultados (Fernandez, 2002: 24; Bel y Fernández, 2002: 124; Torres, 2012: 162). En realidad no existe un precepto legal del que derive directamente una definición de cuentas en participación de la que, a su vez, podamos deducir los caracteres que conforman su estructura jurídica (Martínez, 2011: 110). El concepto ha de extraerse del conjunto del sistema normativo. De la redacción del artículo 239 del Cco. no se puede colegir una definición suficiente -mejoraría, sin duda, si saliese adelante Proyecto de nuevo Código Mercantil $^{23}$; por eso, acudiendo también al resto del articulado, pueden definirse las cuentas en participación como "un contrato en el que una de las partes, denominada partícipe, se interesa en el tráfico mercantil que realiza la otra parte en su propio nombre y bajo su exclusiva responsabilidad, denominada gestor, mediante la realización de una aportación al capital [mejor que de aportación al capital habría que hablar de aportación o participación financiera] y participando de los resultados prósperos o adversos que arroje dicha actividad en la proporción que determinen" (Martínez, 2011: 111). En otro momento, esta misma autora, conceptúa las cuentas como "una fórmula de financiación empresarial mediante la cual, una persona colabora patrimonialmente en el negocio mercantil que ejercita el empresario bajo su

\footnotetext{
${ }^{23}$ En el Anteproyecto de Ley del Código Mercantil, el artículo 545-1 nos ofrece una noción y unos caracteres más precisos:

Artículo 545-1. Noción.

1. Por el contrato de participación una persona, llamada partícipe, se obliga a entregar dinero, bienes o derechos patrimoniales a un operador del mercado, llamado gestor, para destinarlos a una determinada actividad económica en condiciones convenidas.

2. Por el contrato de participación no se crea un patrimonio común ni una personalidad distinta de las que son partes del mismo.

3. La conclusión de un contrato de participación no confiere ni exige del partícipe la condición de empresario u operador del mercado.

4. El contrato de participación tendrá naturaleza mercantil.
}

REVESCO No 122 - Tercer Cuatrimestre 2016 - ISSN: 1885-8031 - www.ucm.es/info/revesco 
exclusivo nombre y responsabilidad participando en los resultados prósperos o adversos que arroje la actividad" (Martínez, 2011: 96).

Como elementos caracterizadores de las cuentas en participación, que pueden deducirse también de la regulación contenida en el Código de comercio, suelen señalarse los siguientes:

- La relación interna que mantienen el gestor y el partícipe (artículos 241 y 242 del $\mathrm{Cco})^{24}$.

- El carácter mercantil de la actividad (artículo 239 Cco.), lo que explicaría su sujeción a lo previsto en el Código de comercio, advirtiendo, no obstante la doctrina, que, así como no ofrece duda que el gestor haya de tener la consideración de comerciante (o empresario), el partícipe podrá no serlo (Martínez, 2011: 124; Martínez Sanz, 2013: 331).

- Ausencia de un patrimonio común ${ }^{25}$.

- Participación en los resultados prósperos o adversos; lo que llevará, entre otras cosas, a que pueda decirse que el partícipe no ostenta un derecho de crédito contra el gestor por el importe de su aportación sino a una cuota de liquidación que lleva, implícitamente, la asunción de posibles pérdidas (Martínez, 2011: 140).

Todos estos rasgos caracterizadores que se predican de las cuentas en participación permiten diferenciarlas de otras figuras afines y resaltar sus potenciales funcionalidades. Las cuentas en participación se pueden distinguir así del préstamo; cuestión que no deja de tener interés, toda vez que en nuestra doctrina científica no han faltado autores que han propuesto la

\footnotetext{
${ }^{24}$ En el Anteproyecto de Ley del Código Mercantil, se encontrará en el Artículo 545-4. Efectos frente a terceros. 1. En el desarrollo de la actividad participada no se podrá adoptar un nombre comercial, razón o denominación social distinta de la del gestor ni usar de más crédito directo que el suyo.

2. Sin perjuicio del conocimiento por terceros de la existencia del contrato de participación, el gestor será el único responsable frente a ellos de la actividad desarrollada en participación.

3. El partícipe no tendrá ninguna acción contra los terceros que contraten con el gestor, salvo en caso de cesión de los derechos de este último frente a aquéllos.

${ }^{25} \mathrm{La}$ ausencia de patrimonio común es la razón fundamental que exponen algunos autores para rechazar que de las cuentas en participación surja un contrato de sociedad (Gadea et al., 2009: 408; Gadea, 2003: 52). En general, dos han sido los argumentos esgrimidos para negar el carácter societario de las cuentas en participación: carecer de un fondo patrimonial común y no tener personalidad jurídica. Sin embargo, en la doctrina científica también se ha podido destacar que ni la existencia de un patrimonio común, ni de actividad común, ni de personalidad jurídica constituyen atributos necesarios del concepto de sociedad. La aceptación en nuestro ordenamiento jurídico de un concepto amplio de sociedad -nos recuerda Fernández de la Gándara, cit., p. 270- por su simplicidad y amplísima vis atractiva, permite albergar toda suerte de fenómenos asociativos con independencia de su identidad causal o estructural, sin que la exigencia legal de un patrimonio común asuma, a estos efectos, la condición de rasgo definitorio del concepto de sociedad (Fernández de la Gándara, 1998: 270). Lo importante en el contrato de sociedad es que todos los miembros de la sociedad colaboren patrimonialmente en la realización del fin social (Sánchez, 2009: 559).
} 
equiparación de ambos contratos, en particular, con la modalidad del préstamo parciario, donde la retribución del prestamista no se estipula como fija, sino proporcional a los resultados.

Se distinguen las cuentas en participación, también, de cualquier fórmula de sociedad irregular, pues no hay patrimonio común ni se crea ni surge ningún fenómeno de personalidad jurídica independiente.

Sin embargo, de todos esos elementos diferenciadores, es la consideración del carácter societario o no de la operación lo que termina siendo clave para poder integrar el régimen jurídico de la figura, cuando apenas el texto legal se limita a enunciarla y cuando la autonomía de la voluntad de las particulares nada tiene predispuesto. De ahí también que la configuración dogmática de la institución, aunque en ocasiones se haya puesto en duda, no deja de tener trascendencia, porque están en juego concretas cuestiones de régimen jurídico.

En efecto, la normativa aplicable a las cuentas en participación, en defecto de lo previsto en los artículos 239 y siguientes del Código de comercio y de lo establecido por las partes, es una de las grandes cuestiones que se mantiene en el debate de las cuentas en participación. La calificación jurídica de las cuentas en participación ha sido una de las cuestiones más debatidas. Si el Código de comercio de 1829 parecía decantarse por su consideración como verdadera sociedad («sociedad accidental» la denominaba), el texto vigente, aunque reproduce lo fundamental de la disciplina, elude esa denominación y sistemáticamente la coloca fuera del Título de las Sociedades Mercantiles ${ }^{26}$, lo que ha propiciado la controversia.

Tradicionalmente venía negándose el carácter societario, entendiéndose que las Cuentas en Participación son un contrato de colaboración o cooperación económica; destacándose el prevalentemente carácter sinalagmático. Sin embargo, hoy, en nuestra doctrina científica, parece predominar la concepción societaria. Significativo, en este sentido, es el cambio que recogerán las nuevas ediciones del Manual de Derecho Mercantil de los profesores Manuel Broseta Pont $(\dagger 1992)$ y Fernando Martínez Sanz. Esto no implica que la polémica esté cerrada. El profesor Vicent Chuliá, distingue la figura del contrato de sociedad,

\footnotetext{
${ }^{26}$ También el Anteproyecto de Ley del Código Mercantil coloca el contrato de participación en el Libro Quinto (De los contratos mercantiles en particular), y no en el Libro Segundo (de las Sociedades Mercantiles), si bien nos advierte en la Exposición de Motivos que "excluye cualquier pronunciamiento legal sobre su naturaleza jurídica".
} 
y considera «errónea y muy peligrosa para la adecuada solución de los frecuentes problemas prácticos que se plantean en el cumplimiento y liquidación del contrato de cuentas en participación su calificación como sociedad interna» (Vicent, 2008: 957). Tampoco en la literatura civilista suele faltar la caracterización de las cuentas en participación como negocio parciario, de naturaleza bilateral y estructura sinalagmática (Tena, 1998: 10684).

En la jurisprudencia de nuestro Tribunal Supremo ha venido predominando la consideración de las Cuentas en participación como un contrato especial, distinto a la sociedad. Sin embargo, no han faltado tampoco manifestaciones del carácter societario de la figura. En particular, nos parece de especial interés la STS de 30 de mayo de 2008 (RJ 3192), donde claramente confirma el carácter societario de la institución, calificando a las cuentas en participación como "una fórmula asociativa entre empresarios individuales o sociales que hace posible el concurso de uno (partícipe) en el negocio o empresa del otro (gestor), quedando ambos a resultas del éxito o fracaso del último”. El Tribunal Supremo, en esta Sentencia, tiene el mérito de reconocer a las cuentas como una modalidad de las llamadas "sociedades internas", a las que en seguida nos referiremos. Sin embargo, esta caracterización no resuelve toda la problemática del régimen jurídico aplicable.

En efecto, a partir de esa consideración societaria, habría que concretar si el régimen ha de integrarse por las normas establecidas en el Código de comercio para las sociedades mercantiles externas, por ser las cuentas en participación una sociedad mercantil, o si, por el contrario, se han de aplicar las normas de la sociedad interna establecidas en el Código civil, por ser las cuentas en participación una sociedad interna. En este último caso, además, como el recurso a la normativa civil de las sociedades internas se revela insuficiente dada la escasa atención que el Código civil (artículo 1669) dedica a las mismas, obligaría a integrar el régimen mediante la aplicación -lógicamente, adaptada a sus características estructurales y funcionales- de las normas que ese cuerpo legal establece para la sociedad externa ${ }^{27}$.

\subsection{El problema de la integración del régimen jurídico. Las cuentas en participación}

Nuestra doctrina científica, ha venido caracterizando a la sociedad interna -frente a la sociedad externa- como aquella que se constituye como un simple vínculo obligatorio sin

\footnotetext{
${ }^{27}$ En la citada STS de 30 de mayo de 2008, el Tribunal Supremo apunta a la aplicación por analogía de las normas de la sociedad civil, solución que, en nuestra opinión, no deja de ser discutible, aunque en el caso entonces enjuiciado la aplicación de las normas mercantiles tampoco habrían llevado a una resolución diferente, (Sánchez, 2009: 561).
} 
trascendencia ad extra, cuya eficacia se despliega únicamente entre quienes la conciertan, sin vocación de relaciones externas unificadas, ni de constituir un patrimonio común, ni de establecer una organización subjetivada para actuar en el tráfico; en definitiva, sin que puedan dar lugar al nacimiento de una personalidad jurídica societaria. Así, todos y cada uno de los supuestos que permite el tipo legal de las cuentas en participación de nuestro Código de comercio son susceptibles de subsumirse, en el ámbito civil, en el tipo de "sociedad interna" del artículo 1669 CC. Entre la sociedad civil interna (1669 CC) y las cuentas en participación no existen de suyo diferencias conceptuales relevantes, ambas se caracterizan con idénticos elementos individualizadores; diferenciándose únicamente por el modelo de operación regulado y su esfera funcional. Por todo ello se dice que las cuentas en participación son el tipo legal de sociedad interna para el ámbito mercantil.

La caracterización societaria de las cuentas en participación permite, ante la ausencia de previsiones legales o de pactos de las partes, integrar su régimen jurídico con las normas del Derecho societario, que probablemente ofrecerán una solución más compatible con la estructura y función de las cuentas en participación que la que pudieran ofrecer las normas generales de las obligaciones y contratos, pensadas esencialmente para los contratos de cambio. Ahora bien, como anticipábamos, la caracterización de las cuentas en participación como "sociedad interna" no resuelve del todo el problema de la integración de su régimen jurídico. La duda es si se han de aplicar las normas establecidas en el Código de comercio para las sociedades mercantiles externas, o si, por el contrario, se han de aplicar las normas de la sociedad interna establecidas en el Código Civil, por ser las cuentas en participación una sociedad interna. La duda no es baladí, pues al no establecerse una precisa regulación de las cuentas en el texto legal, en particular, sobre el régimen de extinción, y toda vez que en el contrato no se haya establecido nada, habrá que integrar el régimen con el de la disolución y consecuente liquidación de sociedades; teniendo que decidir la priorización entre la regulación en las sociedades mercantiles (artículos 218 y 221 del Cco.) o en las sociedades civiles (artículos 1700 y ss. del CC).

Así las cosas, y aun reconociendo que la cuestión no dejará de ser polémica, pensamos que no parece muy lógico anteponer las normas de la sociedad civil externa del Código civil (a las que se llega, como antes apuntamos, vía integración del régimen de la sociedad civil interna, ante la insuficiente regulación que el Código civil dedica a la sociedad civil interna) a las normas para las sociedades mercantiles externas establecidas en el Código de comercio. Y 
el hecho de que el gestor en las cuentas de participación sea una cooperativa no cambia la situación, toda vez que el carácter mercantil de la operación no parece cuestionable.

Como concluye un sector de nuestra doctrina (Colino, 2006: 416-417), la afirmación de que la sociedad civil juega una función residual como sociedad general para el conjunto del ordenamiento jurídico no parece suficiente para eludir el juego del sistema de fuentes impuesto normativamente (arts. 2 y 50 Cco.). La mercantilidad del tipo cuentas en participación -se viene a decir- exige, una vez agotadas las normas específicamente destinadas a la sociedad interna civil, recurrir a las normas de las sociedades colectivas y comanditarias, y sólo cuando no se compaginen con la estructura y función de las cuentas en participación en forma satisfactoria, podrá acudirse a las normas de la sociedad civil externa, para ver si se adecuan mejor a la estructura y función pactada por las partes en las cuentas en participación. Más aún, si nos centramos en la función que desempeñan las cuentas en participación y profundizamos en los elementos estructurales y funcionales que las legislaciones han tipificado, quizá podamos concluir que las diferencias entre las cuentas en participación y las sociedades externas mercantiles no son tan significativas. En este sentido, pensamos, que el recurso a las normas correspondientes a la sociedad civil no pasaría de ser la aplicación residual como norma subsidiaria en los términos del actual artículo 2 del Código de comercio.

Dicho en otros términos, en los supuestos en los que ni los artículos 239 a 243 del Código de comercio ni los pactos de las partes dieran solución, la determinación del régimen que complete la regulación, conforme al sistema de fuentes de los actos de comercio, llevaría a aplicar, en primer término, las disposiciones que resulten adecuadas de las sociedades mercantiles, teniendo en cuenta, no obstante, la naturaleza externa de esas formas de sociedad. Subsidiariamente entrarían en juego las normas correspondientes a la sociedad civil. Sin perjuicio de tener que destacar -como algún autor propone- la fuerte conexión sistemática que el régimen de la sociedad civil, posee -en cuanto residual- en el Derecho de sociedades, no debidamente reflejada -tampoco parece que fuera el lugar- en el artículo 2 del Cco. (Eizaguirre, 2001: 231). 


\section{CONDICIONES PARA LA FORMULACIÓN DE LAS CUENTAS EN PARTICIPACIÓN EN LAS COOPERATIVAS}

Apuntada la virtualidad funcional de las cuentas en participación como fórmula de financiación empresarial y una vez clarificado el marco general de regulación de las misma en nuestro Derecho, quedan por indagar las circunstancias, condiciones o requisitos que procedan, o pueden proceder, para la formulación de las cuentas en una entidad cooperativa. Como vimos, las leyes cooperativas dejan muchas dudas al respecto. Algunas leyes contemplan expresamente la necesidad de acuerdo de la Asamblea General (Cataluña; Extremadura; Navarra), en otras, aunque se recoge la figura, no parece requerirse el acuerdo de ese órgano (Ley de Cooperativas; Asturias; La Rioja; Illes Balears; Castilla-La Mancha; Galicia; Euskadi). Tampoco está claro con quién o con quiénes pueden concertarse las cuentas en participación. En la mayoría de las leyes parece posible que las cuentas en participación se concierten con socios o terceros, pero en alguna legislación parece que solo podrían celebrarse con socios (Castilla y León) o con socios y asociados (Comunidad Valenciana). En fin, tampoco se especifica nada sobre las formalidades del contrato de cuentas en participación.

Aunque, evidentemente, las cuentas en participación no son títulos participativos, ni valores mobiliarios, ni participaciones especiales, comparten con ellos algunos rasgos caracterizadores y mucha de su problemática, por lo que a las incertidumbres o problemáticas, que se nos presentan en la cuentas en participación, quizá podemos buscarles soluciones, también comunes o con una fundamentación análoga, a esos mismos valores.

En este sentido, una de las principales dificultades a la que se enfrenta los títulos participativos -y lo mismo se podría decir de las cuentas en participación- es su compatibilidad con los valores y principios cooperativos. El hecho de que terminen -o puedan terminar- haciendo partícipe del resultado a personas no socias y el hecho que se participe en los resultados en función de la aportación financiera y no de una actividad cooperativizada, es considerado por algún sector doctrinal, contrario a la filosofía cooperativa (Monge, 1999: 735 y 751; Bel y Fernández, 2002: 121; Fernández, 2002: 23; Cabaleiro, 2000: 11), resulta una práctica contraria a los principios cooperativos y distorsiona el carácter de empresa de participación de la sociedad cooperativa, por cuanto los recursos aportados pueden obtener una remuneración generada por la actividad, en la que sus partícipes no participan. Otros, sin embargo, estiman que el legislador ha primado la supervivencia de la cooperativa mediante la 
obtención de recursos precisos para hacer frente a su actividad sobre el interés en mantener la pureza de la filosofía cooperativa y que, además, haciéndolo así "el legislador protege también este último interés ya que la misma existencia de una filosofía cooperativa depende, en última instancia y como es obvio, de la existencia de estas sociedades" (Rocafort, 2010: 154).

En todo este análisis quizá sea conveniente tener en cuenta lo que el profesor Manuel Paniagua recientemente ha identificado como "los modelos ius cooperativos en España" (Paniagua, 2013: 159-205). Ahí se podrá constatar cómo en la vigente Ley 27/1999, de Cooperativas, predomina un modelo ius cooperativo que el profesor Paniagua denomina "economicista". Con este modelo, según recoge la misma Exposición de Motivos de la Ley, se pretenderían reforzar los principios básicos del cooperativismo y, simultáneamente, fortalecer la vertiente empresarial y la solidez financiera de la empresa cooperativa y de la sociedad cooperativa. Para ello, entre otras disposiciones, la Ley propondrá nuevos mecanismos para atraer financiación, entre los que se citan las participaciones especiales y los títulos participativos. Este modelo economicista o funcional de la Ley estatal se replica en la mayoría de las leyes autonómicas; en algunas, incluso, se radicaliza. Es en ese modelo en el que, hoy por hoy, debemos situar las cuentas en participación y sus potencialidades como instrumento de financiación en el ámbito cooperativo. Sin embargo -pensamos nosotros- eso no significa, ni tiene que significar, la conculcación de los valores y de los principios cooperativos que han de guiar siempre la realización de las actividades empresariales de la cooperativa (artículo $1 \mathrm{LC}$ ).

Si el llamado modelo economicista -más o menos atemperado- que se mantiene en la mayoría de nuestras leyes cooperativas, da prioridad a los intereses socioeconómicos de los socios sobre el servicio a fines sociales y de interés general, el reto probablemente sea invertir o atenuar esa prioridad; recuperando la orientación ius cooperativa clásica o social; orientación ésta que, según se nos recuerda, es la más próxima a la "legislación adecuada" que demanda la Constitución española (art. 129.2). En el cumplimiento de esos fines y objetivos sociales probablemente encontremos en las cuentas en participación más puntos en común que lo que a primera vista pudiera parecer. Baste recordar cómo nuestro modelo de financiación, depende en exceso de las entidades bancarias y reclama también modelos alternativos de financiación más cercanos a las personas, más sociales, pudiendo esos nuevos modelos desempeñar, en este sentido, una función social y de interés general nada desdeñable. 
Por todo ello, quizá, lo más conveniente y seguro sea prever en los estatutos la posibilidad de formular cuentas en participación, estableciéndose ahí las circunstancias, condiciones y ámbito en los que proceda su celebración. Y, en cualquier caso, atribuir a la Asamblea General de la cooperativa la competencia para autorizar la celebración de las cuentas en participación a través del correspondiente órgano de representación de la entidad. Previsión estatutaria, pues, y acuerdo de la Asamblea General que, de esa manera, tendrá la posibilidad de valorar las cuantías, condiciones, momento, ámbito subjetivo y objetivo, para la autorización de las cuentas, parece lo más conveniente si queremos asegurar los valores cooperativos y reforzar los principios cooperativos que han de poner en práctica esos valores.

\section{LA LEY 5/2015, DE FOMENTO DE LA FINANCIACIÓN EMPRESARIAL, Y SU INCIDENCIA EN EL ÁMBITO COOPERATIVO. EL PAPEL DE LAS PLATAFORMAS DE FINANCIACIÓN PARTICIPATIVA (CROWDFUNDING)}

Como apuntábamos al comienzo, la Ley 5/2015, de fomento de la financiación empresarial, parte reconociendo los problemas que ha podido generar en la economía española de los últimos años la fuerte dependencia de la financiación bancaria (lo que se conoce como "bancarización”) que -tradicionalmente- han tenido las empresas españolas, particularmente las de menor dimensión. Se considera así necesario un "giro estratégico de la normativa, partiendo de un análisis estricto de sus efectos sobre las diversas fuentes de doble finalidad". Para ello se articulan una serie de medidas, con las que se pretende, además de hacer más accesible y flexible la financiación bancaria a las pymes, "avanzar en el desarrollo de medios alternativos de financiación, sentando las bases regulatorias necesarias para fortalecer las fuentes de financiación corporativa directa o financiación no bancaria en España” (Preámbulo I de la Ley 5/2015, de 27 de abril).

Así, por lo aquí nos interesa y como antes anticipábamos, la Ley introduce importantes novedades en la emisión de obligaciones por las sociedades cooperativas.

Se deroga la Ley 211/1964 de 24 de diciembre, sobre regulación de la emisión por Sociedades que no hayan adoptado la forma de anónimas, asociaciones u otras personas jurídicas y la constitución del Sindicato de obligacionistas; si bien las obligaciones emitidas con arreglo a esa norma, siguen rigiéndose por la Ley de 1964 hasta su extinción (Disposición transitoria décima de la Ley 5/2015). 
Más significativo es la modificación de los artículos 21.2; 32.1 y 54.1 de la Ley 27/1999, de 16 de julio de cooperativas (artículo 44 de la Ley 5/2015). A partir de ahora, la competencia para acordar la emisión de obligaciones y otras formas de financiación mediante valores negociables que no sean títulos participativos o participaciones especiales, y salvo disposición contraria en los estatutos sociales, pasa de la Asamblea General al Consejo Rector. Además, la emisión de obligaciones se regirá, con las adaptaciones que resulten necesarias, por las disposiciones que las regulan para las sociedades de capital (artículos 401 y siguiente del Texto Refundido de la Ley de Sociedades de Capital).

Otra novedad importante de la Ley 5/2015, en la que aquí no nos podemos detener, la constituye la regulación de las Plataformas de Financiación Participativa (PFP), con las que se pretende dar cobertura a algunas de las actividades conocidas como «crowdfunding»; si bien, como se anticipa en el Preámbulo de la Ley, solo pretende regularse las figuras en las que prime el componente financiero de la actividad, en las que el inversor espera recibir una remuneración dineraria por su participación, dejando fuera de la regulación el crowfunding instrumentado mediante compraventas o donaciones. Las PFP servirán así para captar inversores o prestamistas, pero quedan fuera de la consideración de PFP aquellos casos en los que la financiación captada por los promotores provenga exclusivamente de donaciones, venta de bienes y servicios o préstamos sin intereses.

La PFP se vienen a definir en el artículo 46 de la Ley como aquellas empresas autorizadas cuya actividad consiste en poner en contacto, de manera profesional y a través de páginas web u otros medios electrónicos, a una pluralidad de personas físicas o jurídicas que ofrecen financiación a cambio de un rendimiento dinerario (inversores), con personas físicas o jurídicas que solicitan financiación en nombre propio para destinarlo a un proyecto de financiación participativa (promotores).

Los proyectos de financiación participativa se instrumentarán, en los términos que se indican en el artículo 50, a través de las siguientes formas:

- La emisión o suscripción de obligaciones, acciones ordinarias y privilegiadas u otros valores representativos de capital

- La emisión o suscripción de participaciones de sociedades de responsabilidad limitada

- La solicitud de préstamos, incluidos los préstamos participativos. 
Constatamos que no se mencionan otros instrumentos, como las cuentas en participación de las que aquí nos hemos ocupado.

De la regulación prevista para las PFP, interesa resaltar aquí que deberán ser sociedades de capital, contar con la autorización de la Comisión Nacional del Mercado de Valores y cumplir una serie de requisitos para ejercer la actividad, así como otros de tipo financiero (artículos 55 y 56). Quedan, pues, excluidas de la posibilidad de formar PFP las sociedades cooperativas; aunque, evidentemente, nada impide que las cooperativas puedan acudir a alguna de esas plataformas, como promotores, en busca de financiación, siempre que lo hagan en el marco de lo previsto en su respectiva actividad y organización societaria.

\section{CONCLUSIONES}

Con lo que hemos visto podemos, resumidamente, concluir lo siguiente:

1.- La necesidad de financiación constituye un problema recurrente, que se ha agravado por razón de la crisis económica, y que afecta también a las cooperativas. La financiación bancaria en España ha venido ocupando una posición preponderante (bancarización) en relación con otras instancias y mecanismos de financiación. Por ello, en estos momentos se hace más necesario el ensayo de fórmulas alternativas de financiación que permitan reducir la dependencia del sector bancario a la hora de obtener financiación.

2.- La legislación cooperativa en España pone a disposición de esas entidades diversos instrumentos de financiación o de captación de recursos, aunque no siempre con la atención adecuada. La Ley 5/2015, de 27 de abril, de fomento de financiación empresarial, introduce importantes novedades en lo referente a la emisión de obligaciones que afectarán, también, a la emisión de obligaciones por las sociedades cooperativas. No obstante, aun siendo necesarias las modificaciones y novedades que esta Ley nos ofrece, no parece que vayan a ser suficientes para dar soluciones al sector del cooperativismo que busca, también, una financiación externa y, en cierta medida, alternativa.

3.- Entre esos instrumentos de financiación disponibles, la mayor parte de la legislación cooperativa española alude a las cuentas en participación, que se mencionan como una posible forma de financiación de las cooperativas. Sin embargo, no se concreta su régimen, remitiéndose, en general, a lo que dispone el Código de comercio, lo que, hoy por hoy, resulta insuficiente.

REVESCO No 122 - Tercer Cuatrimestre 2016 - ISSN: 1885-8031 - www.ucm.es/info/revesco 
4.- Es necesario clarificar el régimen de la cuentas en participación -o contrato de participación como se llama en el Anteproyecto de Ley del Código mercantil-, pues el éxito o el fracaso de los instrumento o técnicas de financiación, depende, también, de la fácil comprensión de los potenciales inversores.

5.- La determinación de la naturaleza jurídica de las cuentas en participación ha sido siempre objeto de debate doctrinal. El carácter societario o no de la operación termina siendo clave para poder dar solución al problema de la integración del régimen jurídico de la figura. Últimamente predomina su caracterización societaria, lo que, en nuestra opinión, resulta más compatible con su estructura y funcionalidad.

6.- El Anteproyecto de Ley del Código mercantil se presenta como una oportunidad que no se debería desperdiciar- para la clarificación del régimen jurídico de las cuentas en participación. Clarificación que, seguramente, redundaría en una mejor y eficaz utilización de la figura como mecanismo de financiación. En particular, en la regulación propuesta en ese Anteproyecto, se sigue echando en falta la concreción de un régimen de extinción del -ahora llamado- contrato de participación.

7.- En cualquier caso, la legislación cooperativa española debería recoger en su articulado las especialidades en la regulación de las cuentas en participación que fueran de aplicación para el supuesto en que se concertaran por las sociedades cooperativas.

Es conveniente, también, que la legislación cooperativa recoja, expresamente, la pertinente cobertura estatutaria para la utilización de las cuentas en participación por parte de las cooperativas. Para la aprobación de las cuentas en participación consideramos necesario un acuerdo de la Asamblea General, como máximo órgano de la entidad, quien habrá de valorar y decidir las condiciones y circunstancias en las que proceda la formulación de las cuentas en participación por los representantes de la entidad.

\section{BIBLIOGRAFÍA}

ALEMANY, L., ALVAREZ, C.; PLANELlAS, M.; URBANO, D. (2011) Libro Blanco de la Iniciativa Emprendedora en España, Barcelona: Fundación Príncipe de Girona.

BEL DURÁN, P. y FERNÁNDEZ GUADAÑO, J. (2002) La financiación propia y ajena de las sociedades cooperativas. CIRIEC-España, Revista de Economía Pública, social y Cooperativa, $\mathrm{N}^{\mathrm{o}}$ 42, pp. 101-130. 
CABALEIRO CASAL, M. J. (2000) La intercooperación de las sociedades cooperativas: su aplicación en el desarrollo rural de la Comunidad Autónoma de Galicia. Vigo: Universidad de Vigo.

CELAYA ULIBARRI, A. (1995) Acceso de las cooperativas al mercado de capitales. Mondragón.

COLINO MEDiaVilla, J. L. (2006) Voz Cuentas en Participación. En ALONSO LEDESMA, C. (DIR $\left.{ }^{\mathrm{a}}\right)$ Diccionario de Derecho de Sociedades. Madrid: Iustel, pp. 413419.

EMBID IRUJO, J. M. (2001) En Prologo a MARTÍNEZ BALMASEDA, A. Las cuentas en participación y su vertiente interna. Granada: Editorial Comares, pp. XV-XIX.

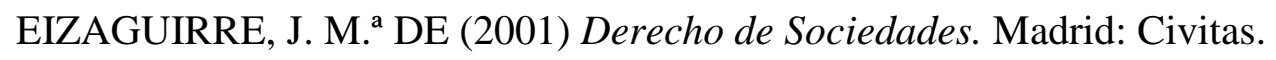

FERNÁNDEZ DE LA GÁNDARA, L. (1998) Las Cuentas en Participación: Un ensayo de caracterización dogmática y funcional. En AA.VV. Estudios de Derecho Mercantil homenaje al profesor Justino Duque Domínguez. Valladolid: Universidad de Valladolid, vol. I, pp. 259-313.

FERNANDEZ GUADAÑO, J. (2002) La nueva estructura financiera de acuerdo con la Ley 17/1999, de cooperativas. REVESCO. Revista de Estudios Cooperativos, No 77, pp. 7-28.

GADEA SOLER, E. (2003) La Financiación de las Sociedades Cooperativas un estudio desde la perspectiva de la Ley de Cooperativas del País Vasco. Boletín de la Asociación Internacional de Derecho Cooperativo. № 37 (Ejemplar dedicado a: La Financiación de las Cooperativas), pp. 37-54.

GADEA, E.; SACRISTÁN, F.; VARGAS VASSEROT, C. (2009) Régimen jurídico de la sociedad cooperativa del siglo XXI. Realidad actual y propuesta de reforma. Madrid: Dykinson.

LÓPEZ SANTANA, N. (2013) En José Ignacio PEINADO GARCÍA y Trinidad VÁZQUEZ RUANO. Tratado de Derecho de cooperativas, T. I. Valencia Tirant lo Blanch, pp. 630643.

MARÍN LÓPEZ, J. J. (1999) Recientes reformas de la legislación cooperativa. Noticias de la Economía social y cooperativa, No 29, CIRIEC, pp. 39-54.

MARTÍNEZ BALMASEDA, A. (2011) Las cuentas en participación y su vertiente interna. Granada. Editorial Comares.

MARTÍNEZ BALMASEDA, A. (2014) Algunos aspectos jurídico-mercantiles tras el concurso de Fagor. CIRIEC-España. Revista Jurídica de Economía Social y Cooperativa. $\mathrm{N}^{\mathrm{o}} 25, \mathrm{pp} .281-311$. 
MARTÍNEZ SANZ, F. (2013) En Manuel BROSETA PONT y Fernando MARTÍNEZ SANZ, Manual de Derecho Mercantil, 20ª ed. V. I. Madrid: Tecnos.

MONGE GIL, A. L. (1999) Algunas reflexiones a propósito y sobre la Ley de Cooperativas de Aragón. Revista de Derecho Mercantil. N²32, pp. 723-754.

MORILLAS JARILLO, Ma . J. y FELIÚ REY, M. I. (2002) Curso de Cooperativas. Madrid: Tecnos, 2. ${ }^{\mathrm{a}}$ ed.

PANIAGUA ZURERA, M. (2005) Las sociedades cooperativas. Las sociedades mutuas de seguros y las mutualidades de previsión social, en JIMÉNEZ SÁNCHEZ, G. (coord.), Tratado de Derecho Mercantil, La sociedad cooperativa. Las sociedades mutuas y las entidades mutuales. Las sociedades laborales. La sociedad de garantía recíproca, vol. I. Madrid: Marcial Pons.

PANIAGUA ZURERA, M. (2013) La sociedad-empresa cooperativa en la evolución de los modelos ius cooperativos en España. Revista de Derecho de Sociedades. No 40, pp. 159205.

ROCAFORT NICOLAU, A. (2010) La financiación cooperativa mediante la emisión de títulos participativos. CIRIEC-España, Revista de Economía Pública, social y Cooperativa. $\mathrm{N}^{\mathrm{o}}$ 68, pp. 141-166.

RODRÍGUEZ DÍAZ, I. (1999) Las cuentas en participación como alternativa para la financiación de las sociedades de responsabilidad limitada: especial referencia a su utilidad en las sociedades familiares. Actualidad Civil, Sección Crónica, Ref. XXIX, T. 2.

SÁNCHEZ PACHÓN, L. A. (2009) Las Cuentas en Participación como fórmula asociativa. Improcedencia de la restitución de la aportación sin previa extinción y liquidación del vínculo societario. Cuadernos Civitas de Jurisprudencia Civil. № 80, pp. 549-570.

SÁNCHEZ PACHÓN, L. A. (2011) Los acuerdos intercooperativos. Un instrumento jurídico para la colaboración en momentos de crisis. CIRIEC-España. Revista Jurídica de Economía Social y Cooperativa. № 22, pp. 121-149.

TENA PIAZUELO, I. (1998) El contrato de cuentas en participación y su distinción con la sociedad civil irregular. Revista General de Derecho. № 648, pp. 10663-10690.

TORRE OLMO, B. (2013) Financiación de la empresa en el contexto actual". Cursos de verano de la Universidad de Cantabria. Empresa y empleo: estrategias de futuro responsable.

http://personales.unican.es/diazb/Bego\%C3\%B1a\%20Torre\%20Olmo\%2024\%20de\%20ju nio\%202013.pdf 
TORRES PÉREZ, F. J. (2012) Régimen jurídico de las aportaciones sociales en la sociedad cooperativa. Cizur Menor: Thomson Reuters-Aranzadi.

VALENZUELA GARACH, F. (2013) En José Ignacio PEINADO GARCÍA y Trinidad VÁZQUEZ RUANO, Tratado de Derecho de cooperativas, T. I. Valencia: Tirant lo Blanch, pp. 620-630.

VICENT CHULIÁ, F. (2008): Introducción al Derecho Mercantil. Valencia: Tirant lo Blanch, $21^{\mathrm{a}} \mathrm{ed}$. 